\title{
Combined effects of environmental stressor in the aquatic environment
}

\author{
Maria João Bebianno • Christophe Minier
}

Received: 8 July 2014 / Accepted: 17 July 2014 / Published online: 12 September 2014

(C) Springer-Verlag Berlin Heidelberg 2014

A large variety of traditional contaminants including metals, hydrocarbons, halogenated hydrocarbons and pesticides, and emerging compounds (pharmaceuticals, personal care products, plastics, and nanoparticles) are generally found in the marine environment. These compounds are of special concern due to their intensive use and threats they can cause to the aquatic environment and human health. Moreover, climate change can also have an additional impact on the effects of these compounds. Due to the complex nature of these stressors, a great deal of research has been carried out to develop the best analytical technologies for the detection of these compounds in the aquatic environment and for assessing their biological effects.

This special issue is a collection of key articles addressing field and analytical aspects of multiple stressors in the aquatic environment presented to the 17 th meeting on pollution Responses in Marine Organisms (PRIMO17) held at the University of Algarve (Portugal) from the fifth to the eighth of April 2013. This International Symposium series, Pollutant Responses in Marine Organisms (PRIMO) began in 1981 with a small group

Responsible editor: Philippe Garrigues

17th International Meeting on Pollution Responses in Marine Organisms

M. J. Bebianno $(\bowtie)$

Centre of Marine and Environmental Research (CIMA), Faculty of

Science and Technology, University of Algarve, Campus de

Gambelas, 8000 Faro, Portugal

e-mail: mbebian@ualg.pt

C. Minier

National Agency for water and Aquatic Ecosystems (ONEMA),

University of Le Havre, Hall C - 5 square Félix Nadar, 94

300 Vincennes, France

e-mail: christophe.minier@onema.fr of NSF-funded researchers from Woods Hole Oceanographic Institution and from Plymouth Marine Laboratory who were addressing questions related to Chemical Effects and the Health of the Ocean. The first PRIMO Symposium was held in Plymouth, UK, in 1981 and addressed the mechanistic aspects of the same topic with the goal of stimulating international scientific interactions in this area. The success of the first PRIMO meeting led to biennial meetings held alternately in Europe, the USA, and South America. PRIMO meetings have been held in 13 cities of 8 countries: the UK (Plymouth 1981, 1985, 1989, 2001), the USA (Woods Hole, MA 1983, 1987, 1991; Asilomar Monterey, CA 1995; Williamsburg, VA 1999; Tampa, FL 2003 and Long Beach, CA, 2011), Sweden (Goteborg, 1993), Norway (Bergen, 1997), Italy (Alessandria, 2005), Brazil (Florianópolis, 2007), and France (Bordeaux, 2009). Although the word "marine" was used to produce the memorable acronym, the research presented has never distinguished between marine and freshwater, and always included research results from marine and freshwater organisms. The overall theme of PRIMO17 was dedicated to the impacts of large scale problems such as Ocean and Human Health, global climate change, ocean acidification, effects of multiple stressors from emerging contaminants to nanoscale materials, and mechanistic effects of toxicity from ecosystem scale to the exposome (www.cima.ualg.pt/ primo17).

The meeting was characterized by the following major scientific themes: climate change; ocean acidification; emerging compounds (nanomaterials, pharmaceuticals, personal care products (PPCPS)); combination effects of multiple stressors; detection and monitoring of deliberately dumped chemicals at sea; endocrine disruption; cellular absorption, distribution, metabolism, and elimination; tissue levels and immune responses; biomarkers; 
ecotoxicology of large marine vertebrates; exposome and exposomics; geno- and phenotoxicity; epigenetic; computation toxicology; ecosystem-level effects; and environmental assessment.

PRIMO17 brought together more than 350 participants including academics, researchers, professionals, and policymakers from 32 countries of all continents, $36 \%$ of which were young scientists. These are outstanding numbers when compared with previous PRIMO meetings, clearly reflecting the dynamism and scientific quality of these meetings.

The outcome of the discussions on the advancement of the understanding of the effects of multiple stressors in the marine environment will contribute to advise decisionmakers on the policy to improve the quality of the aquatic environment.

We look forward to the next meeting to be held in Norway in 2015 .

Acknowledgments The PRIMO17 Organizing Committee would like to extend our sincere thanks to Environmental Science and Pollution Research Editor-in-Chief Philippe Garrigues and to Springer, the journal's publisher, for their full support to PRIMO17. We would like to thank the Portuguese American Foundation, the Organization for the Prohibition of Chemical of Weapons (OPWS), ICES, the Lisbon Oceanário, Zoomarine, and Sparus for their support in giving grants to the invited speakers and in supporting the best presentation and posters of young scientists. Finally, we also want to thank, the Faculty of Science and Technology, the Faculty of Economy as well as the Research Centre of Marine and Environmental Research (CIMA) and the University of Algarve for their support.

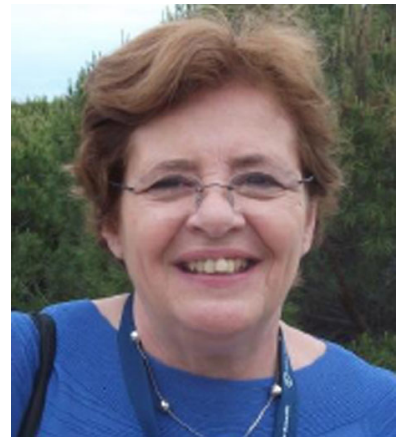

M. J. Bebianno is currently a full professor of Aquatic Pollution and Ecotoxicology at the University of Algarve, the most prestigious University in Portugal working on Marine Sciences and develops her research at the Centre of Marine and Environmental Sciences (CIMA) of the same University. She got her $\mathrm{PhD}$ from the University of Reading in the UK and joined the University of Algarve in 1985. She has over 150 publications in peerreviewed original research articles in top international journals. She has been invited to give seminars at numerous prestigious universities and international conferences. Her research interest focused on the effects of old traditional and emerging contaminants in the marine environment using traditional biomarkers and "omics" approach.

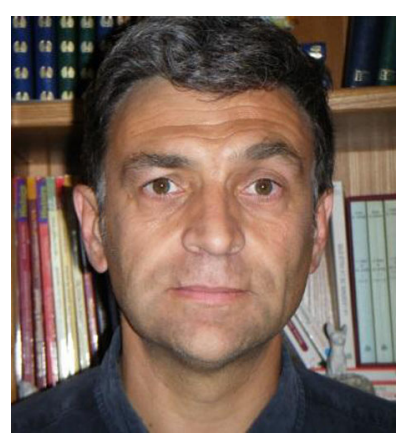

C. Minier is a full professor of Normandy University leading the Laboratory of Ecotoxicology which recently merged with other groups to form the largest group working in Ecotoxicology in Northern France (UMR-I SEBIO). He has over 50 publications in peer-reviewed journals focusing on mechanistical studies on the multixenobiotic resistance system, endocrine disruption, and the immune system. He recently moved to the French National Agency of Water and Aquatic Ecosystems (ONEMA) as co-director of the scientific and technical department supervising four research departments across France. 